\title{
Upper Extensor Surface
}

National Cancer Institute

\section{Source}

National Cancer Institute. Upper Extensor Surface. NCI Thesaurus. Code C147165.

Pertaining to the upper portion of the surface on the opposite side of the joint when it bends. 